\title{
Association of HLA and post-schistosomal hepatic disorder: A systematic review and
}

\section{meta-analysis}

Running title: HLA and Post-schistosomal Hepatic Disorder

Nguyen Tien Huy ${ }^{1}$, Mohamed Hamada ${ }^{2}$, Mihoko Kikuchi ${ }^{1,3}$, Nguyen Thi Phuong Lan ${ }^{4}$, Michio Yasunami $^{1}$, Javier Zamora ${ }^{5}$, and Kenji Hirayama ${ }^{1,6, *}$

${ }^{1}$ Department of Immunogenetics, Institute of Tropical Medicine (NEKKEN), Nagasaki University, 1-12-4

Sakamoto, Nagasaki 852-8523, Japan

${ }^{2}$ Zoology Department, Faculty of Science, Cairo University, Cairo 12613, Egypt

${ }^{3}$ Center for International Collaborative Research, Nagasaki University (CICORN), 1-12-4 Sakamoto, Nagasaki 852-8523, Japan

${ }^{4}$ Department of Immunology and Microbiology, Pasteur Institute of Ho Chi Minh City, 167 Pasteur Street,

Dictrict 3, Ho Chi Minh City, Vietnam

${ }^{5}$ Clinical Biostatistics Unit, Ramón y Cajal Hospital and CIBER Epidemiologia y Salud Publica (CIBERESP), Spain

${ }^{6}$ Global COE program, Nagasaki University, Japan

*To whom correspondence should be addressed. E-mail: hiraken@nagasaki-u.ac.jp (Kenji Hirayama)

\section{Authors' contributions}

Conceived and designed the experiments: NTH KH. Analyzed the data: NTH MH MK NTPL JZ KH. Contributed reagents/materials/analysis tools: NTH MH MK NTPL MY JZ KH. Wrote the paper: NTH MH NTPL JZ KH. 


\section{Keywords}

Genetic, hepatic disorder, HLA, meta-analysis, schistosomiasis

\section{Email address and phone number of contributing authors}

Nguyen Tien Huy, tienhuy@nagasaki-u.ac.jp

Mohamed Hamada, $\underline{\text { m_hamada_mi@yahoo.com }}$

Mihoko Kikuchi, mkikuchi@nagasaki-u.ac.jp

Nguyen Thi Phuong Lan, planpasteur@yahoo.com

Michio Yasunami, yasunami@nagasaki-u.ac.jp

Javier Zamora, javier.zamora@hrc.es

Kenji Hirayama, hiraken@nagasaki-u.ac.jp 


\section{ABSTRACT}

Several human genetic variants, HLA antigens and alleles are reportedly linked to post-schistosomal hepatic disorder (PSHD), but the results from these reports are highly inconclusive. In order to estimate overall associations between human genetic variants, HLA antigens, HLA alleles and PSHD, we systematically reviewed and performed a meta-analysis of relevant studies in both post-schistosomal hepatic disorder and post-schistosomal non-hepatic disorder patients. PubMed, Scopus, Google Scholar, The HuGE Published Literature database, Cochrane Library, and manual search of reference lists of articles published before July 2009 were used to retrieve relevant studies. Two reviewers independently selected articles and extracted data on study characteristics and data regarding the association between genetic variants, HLA antigens, HLA alleles and PSHD in the form of $2 \times 2$ tables. A meta-analysis using fixed-effects or random-effects models to pooled odds ratios (OR) with corresponding 95\% confidence intervals were calculated only if more than one study had investigated particular variation. We found 17 articles that met our eligibility criteria. Schistosoma mansoni and Schistosoma japonicum were reported as the species causing PSHD. Since human genetic variants were only investigated in one study, these markers were not assessed by meta-analysis. Thus, only HLA-genes (a total of 66 HLA markers) were conducted in the meta-analysis. Our meta-analysis showed that human leucocyte antigens HLA-DQB1*0201 $(\mathrm{OR}=2.64, P=0.018), \mathrm{DQB} 1 * 0303(\mathrm{OR}=1.93, P=0.008)$, and DRB1*0901 $(\mathrm{OR}=$ 2.14, $P=0.002)$ alleles and HLA-A1 $(\mathrm{OR}=5.10, P=0.001), \mathrm{A} 2(\mathrm{OR}=2.17, P=0.005), \mathrm{B} 5(\mathrm{OR}=4.63$, $P=0.001), \mathrm{B} 8(\mathrm{OR}=2.99, P=0.02)$, and $\mathrm{B} 12(\mathrm{OR}=5.49, P=0.005)$ serotypes enhanced susceptibility to PSHD, whereas HLA-DQA1*0501 (OR $=0.29, P=<0.001)$ and DQB1*0301 (OR = 0.58, $P=0.007)$ 
were protective factors against the disease. We further suggested that the DRB $1 * 0901-\mathrm{DQB} 1 * 0201$, DRB1*0901-DQB1*0303 and A1-B8 haplotypes enhanced susceptibility to PSHD, whereas DQA1*0501-DQB1*0301 linkage decreased the risk of PSHD. The result improved our understanding of the association between the HLA loci and PSHD with regard to pathogenic or protective T-cells and provided novel evidence that HLA alleles may influence disease severity. 


\section{Introduction}

Schistosomiasis is well established as a major health problem in Africa, Asia, and South America [1]. Each year, more than 250,000 deaths are reported from an estimated 200 million individual sufferers [2,3] due to complications of chronic schistosomiasis-related liver disease [4]. Chronic schistosomiasis-related liver disease is caused by Schistosoma mansoni and Schistosoma japonicum. The disease is characterized by periodic activation of the host immune system against fluke eggs that were deposited in the intestinal wall veins and then delivered to the liver by the blood flow, resulting in granuloma formation and peri-portal fibrosis [5]. Peri-portal fibrosis can cause portal blood hypertension, venous obstruction, splenomegaly, esophageal varices, ascites, hematemesis, and congestive heart failure resulting in death in the absence of proper treatment [5].

Schistosomicides are generally administered with the aim of killing the parasite and preventing against re-infections, while waiting the excretion of tissue-dwelling eggs. However, only one schistosomicide, praziquantel, has been used in large-scale controlled programs, raising concerns about the development of drug resistance [6]. Therefore, it is necessary to study the molecular, biochemical, and immunological aspects of schistosomiasis to develop vaccines and new treatments.

The pathogenesis of peri-portal fibrosis is not yet completely understood. Host immunity, including suppressed Th1/predominant Th2 profiles [7,8], changes in cytokine production [9,10], T-cell responses [11,12], and B-cell responses [13], has been extensively analyzed as a factor that is potentially responsible for fibrotic development. In addition, host genetic background is considered a potential risk factor 
contributing to disease development [14-16]. Although associations between post-schistosomal hepatic disorder (PSHD) and HLA antigens, HLA alleles, and genetic variations have been reported in individual studies, the associations are not observed consistently across studies. Therefore, the present study was conducted to estimate overall associations between human genetic variants, HLA antigens, HLA alleles and PSHD by systemic review and meta-analysis of relevant studies in both post-schistosomal hepatic disorder and post-schistosomal non-hepatic disorder patients. 


\section{Methods}

\subsection{Search strategy and study selection}

A protocol was designed before this study was performed as recommended by the PRISMA statement (http://www.prisma-statement.org/statement.htm). In July 2009, five electronic databases: PubMed (http://www.ncbi.nlm.nih.gov/sites/entrez), Scopus (http://www.scopus.com/scopus/home.url), Google Scholar (http://scholar.google.com/), The HuGE Published Literature database (http://hugenavigator.net/HuGENavigator/startPagePubLit.do), and the Cochrane Library (http://www.cochrane.org) were searched for suitable studies. The search terms used for PubMed and Scopus were as follows: “("gene variant" OR polymorphism OR SNP OR genotyp* OR "Case control study" OR Haplotype OR "linkage disequilibrium" OR "genetic risk") AND schistosom*” (OR was used in the literature search as a connect word). We used "schistosoma OR schistosomiasis OR schistosome" to search in Cochrane Library and The HuGE Published Literature database. For the "Advanced Scholar Search", we used "schistosoma OR schistosomiasis OR schistosome” to fill in the field "with all of the words”, "genetic polymorphism variant SNP genotype Haplotype disequilibrium” to fill in the field "with at least one of the words", and "where my words occur" in the field "title of article". We further supplemented these searches with a manual search of reference lists and citation list using the Scopus databases. For each identified gene, we performed gene-specific searches by replacing the genetic terms with gene name terms.

We sought only articles that evaluated the association between post-schistosomal hepatic disorder (PSHD) and human genetic variants, HLA antigens, or HLA alleles. No restrictions were made with 
respect to language, patient age (children or adult), gender, or study design (family-based association studies or population designs that use un-related individuals). Since a number of zero event were found in several variants from included studies, and a meta-analysis method of adding 0.5 to cells with zero event creates estimation problems if the sample size is too small. We excluded studies with fewer than 20 participants (at least 10 cases and 10 controls were required for inclusion) to limit selection bias [17] and reduce the effect of adding 0.5 to cells with zero event on the result less than $5 \%$. Furthermore, studies were also excluded for any of the following reasons: (1) studies that were reported as animal studies, case reports, scientific correspondence, or reviews; (2) studies from which data could not be reliably extracted; (3) studies that used healthy individuals or other severe forms of schistosomiasis as the control group.

Initially, two independent reviewers (Huy and Hamada) scanned primary titles and abstracts (when available) to select potential full text articles for further scrutiny. When the title and abstract could not be rejected by any reviewer, the full text of the article was obtained and carefully reviewed for inclusion by the two reviewers. Inclusion or exclusion of each study was determined by discussion and consensus between the two reviewers.

\subsection{Data management}

Full-text versions of all papers eligible for inclusion were obtained and, after the inclusion was confirmed, data were extracted by two independent investigators (Huy and Hamada). The data extracted included the first author, year of publication, study design (family-based or case-control), country of 
origin, source of the samples (clinic-, hospital-, or community-based), number of included individuals, gender ratio, and age at examination of included individuals.

In cases where genotype or allele distributions were not provided or data contained obvious errors in the original publication (such as typographical errors, switched allele frequencies, or incorrect allele designations), we attempted to clarify the discrepancy directly with study authors, generally by contacting the first and last authors twice via e-mail. Studies for which we could not obtain clarification or genotype information (after at least two attempts by e-mail) are listed as “no data available”.

\subsection{Duplicate publications}

Papers published by same research group and studying the same genetic variation or HLA types were checked for potential duplicate data. Whenever data overlap was suspected, authors were contacted via e-mail and asked for clarification. If no clarification could be obtained (for example, if we received no answer after at least two attempts by e-mail), data sets were considered as overlapping, and the largest data set was used for meta-analysis.

\subsection{Meta-analysis}

Meta-analyses for population designs and for family studies were performed separately [18,19] using Comprehensive Meta-analysis software version 2.0 (http://www.meta-analysis.com). For each genetic variation or HLA types, $2 \times 2$ tables were generated, and the odds ratio (OR) for particular allele was 
computed. Heterogeneity between studies was evaluated using the $Q$ statistic and $I^{2}$-test. Heterogeneity was considered statistically significant if $P$ was less than 0.10 [20]. $I^{2}$ values $>25 \%$, 50\%, or $75 \%$ are considered as low, moderate, or high heterogeneity, respectively [21]. Pooled OR with the corresponding 95\% confidence intervals $(95 \% \mathrm{CI})$ was calculated only if more than one study had investigated a particular allele. A fixed-effects model with weighting of the studies was used when there was a lack of significant heterogeneity $(P>0.10)$, while a random-effects model with weighting of the studies was used when there was heterogeneity between studies $(P \leq 0.10)$ [22]. Adjustment of $P$ value for multiple comparisons was not conducted because it may increase the likelihood of type II errors [23,24]. In order to reduce the false discovery rate, a confidence interval and interpretation of across studies are proposed to give complement information to $\mathrm{P}$ value. Therefore, in the present study, statistical significance was defined as $P$ value was $<0.05$ (two-tailed test) and the 95\%CI of OR did not overlap 0.9-1.1, in combination with replicated direction in results across studies.

Finally, to assess the presence of publication bias statistically, we performed Egger's regression test where there were three or more studies assessing the effect of a particular allele on the development of PSHD $[25,26]$. Publication bias was considered significant when the $P$ value was $<0.1$. Publication bias was further evaluated by Begg's modified funnel plot where there were five or more studies assessing the effect of a particular allele [27]. 


\section{Results}

\subsection{Study characteristics}

Our literature searches identified 395, 578, 303, and 33 publications in the initial searches of PubMed, Scopus, Google Scholar, and HuGE Published Literature, respectively (Fig. 1). After screening the title and/or abstract, 79 articles were selected for full text reading. We further identified additional studies by searching reference lists and tracking articles citing relevant publications using the Scopus databases from the selected full text studies, review articles, and textbook chapters. A total of 62 articles were excluded from the 79 articles that were read in full for one of the following reasons: (1) Leishmaniasis association ( $n=1)$, (2) review/conference/book/thesis ( $n=15)$, (3) genetic studies of parasite $(n=6)$, (4) no genetic association ( $n=2)$, (5) animal research ( $n=1)$, (6) no patient with hepatic disorder $(n=25)$, (7) negative control was intestinal or cerebral schistosomiasis $(n=2)$, (8) negative control was healthy group or non-schistosomiasis ( $n=2)$, (9) co-infection with hepatitis C or HIV (n=2), (10) unable to extract data and no response after contacting the authors via email $(n=3)$ [28-30], and (11) overlapping studies $(n=3)$ [31-33]. Finally, 17 studies were selected for final analysis [16,34-49].

The characteristics of the studies in this meta-analysis are outlined in Table 1. Most of the studies were case-control studies of un-related individuals $(\mathrm{n}=16)$; only one was a family-based study. More studies were performed among Africans $(n=9)$ and Asians $(n=7)$ than among South Americans $(n=1)$. Ten studies investigated S. mansoni, while other 7 studies did on S. japonicum. Ten studies did not stated the gender information of subjects, all remained studies $(n=7)$ showed dominant male in both PSHD and control 
groups. Nine studies included adults [16,35-37,40-43,48], three studies enrolled children subjects

[44,46,49], one study recruited both adults and children [34], and four studies did not mention this information [38,39,45,47]. A total of three different methods for PSHD diagnosis (ultrasound: $n=10$, biopsy: $n=2$, clinical diagnosis $n=4$ ) were performed in 16 of 17 studies. One study did not mention the method for PSHD diagnosis [35]. Concerning the ultrasound for PSHD diagnosis, one study did not describe in detail [16], while the remaining studies used the WHO ultrasound criteria [50]. Only two studies took in consideration the prevalence of each variant in the general population $[34,36]$. The human leucocyte antigens (HLA) loci were investigated in 11 studies, while cytokines and other signal protein genes were investigated in six studies.

\subsection{Meta-analysis}

Since only one study investigated cytokine and other related protein genes, these markers were not assessed by meta-analysis. Thus, only HLA-types (a total of 66 HLA markers) were included in the meta-analysis as shown in Table 2. Pooled ORs showed that eight HLA variants-DQB1*0201, DQB1*0303, DRB1*0901, A1, A2, B5, B8, and B12—were associated with a significant increase in risk for PSHD, while DQA1*0501 and DQB1*0301 were associated with a significant decrease in risk for PSHD $(P<0.05)$ (Fig. 2). The negative association of DQA1*0501 and PSHD was consistent among two studies $\left(P\right.$ value for heterogeneity $=0.48, I^{2}=0$ ) (Table 2 and Fig. 2A), whereas A1 and B5 were found associated with PSHD among two and three of five studies, respectively (Table 2 and Fig. 2B). The positive association DQB1*0201 and DRB1*0901 with PSHD were found to be significant in one study 
but not significant in another study with no evidence of significant heterogeneity between two studies (Table 2 and Fig. 2A). Similarly, DQB1*0301, DQB1*0303, A2, B8, and B12 were found to be significant in one study but not in two or three other studies. Significant heterogeneity among studies of the A1 and B5 antigens was found; however, based on the results of analysis using the random effect model, the risk of PSHD was significantly higher in carriers of these variants.

We further evaluate the effect of different schistosomal species on the significant association between HLA types and PSHD. All HLA variants-DQB1*0201, DQB1*0303, and DRB1*0901 were associated with S. japonicum-induced PSHD in all studies, while HLA antigens-A1, A2, B5, B8, and B12 were correlated with S. mansoni-induced PSHD in all studies except one study by Wang et al. (Table 1 and Fig. 2). Removing the study by Wang et al. had little effect on the significant association $(P<0.05)$, pooled ORs and 95\%CIs (data not shown). 


\section{Discussion}

Our pooled results suggested that HLA-A1, -B8, DQB1*0201 are associated with increased risk of PSHD (Table 2 and Fig. 2B). Furthermore, these alleles are reportedly associated with the severity of other granulomatous diseases [51-53], suggesting that the mechanism of PSHD development shares some similar part of other granulomatous diseases.

The frequency of the HLA-DQB1*0201 allele was higher in PSHD patients in Zhang's study (OR =5.83, $P=0.009)$ and Hirayama's study $(\mathrm{OR}=1.68, P=0.31)$ when compared to the control patients (Fig. 2A). This trend was also observed in the study by Secor et al. [29], which was not included in this analysis due to un-extractable data, further supporting this association. The DQB $1 * 0201$ allele has been also linked to the progression of cirrhosis due to hepatitis C virus (HCV) [54], the elevation of alanine aminotransferase levels in serum (a marker of the hepatic damage) [55], the risk of anti-tuberculosis drugs-hepatotoxicity [56], the severity of the intestinal mucosal damage [57], and the risk of several autoimmune disorders [58,59]. Furthermore, autoimmunity has also been proposed as a factor in the development of schistosomiasis-associated hepatic disease [60]. It has also been shown that human papillomavirus-16 E7 (aa 71-85) peptide presented to some pathogenic T cells resulted in dysplastic cervical lesions in individuals carrying HLA-DQB1*0201 [61]. Therefore, HLA-DQB1*0201 may play a role in the antigen presentation to some pathogenic T-cells that could enhance the development of PSHD.

Another HLA-DQB1 allele, DQB1*0303, has also been associated with PSHD $(\mathrm{OR}=1.93,95 \% \mathrm{CI}=$ 1.19-3.14, $P=0.008$ ). There may be a closely linked variant (possibly in the HLA-DRB1 locus) that is primarily responsible for the PSHD susceptibility and associated with these DQB1 alleles. A number of 
studies have demonstrated DRB1*0901-DQB1*0201 [62-64] and_DRB1*0901-DQB1*0303 linkage [41,65] are common in African and Asian populations. The DRB1*0901 allele was also associated with susceptibility to PSHD $(\mathrm{OR}=2.14,95 \% \mathrm{CI}=1.31-3.48, P=0.002)$. The possibility that the HLA-DRB1*0901 allele is primarily responsible for PSHD susceptibility is an interesting point to be considered because IgG4 elevation has been found in individuals with the HLA-DRB1*0901 allele [66] and is positively linked to several systemic fibrosis conditions [67] and schistosomiasis peri-portal fibrosis [68]. It is probable that patients with HLA-DRB1*0901 are prone to produce B cells for specific IgG4 and Th2 cells that are reactive to schistosomal antigens.

The HLA-DQA $1 * 0501(\mathrm{OR}=0.29,95 \% \mathrm{CI}=0.17-0.50, P<0.001)$ allele was identified as a resistant allele for PSHD in two studies [37,42]. Furthermore, Trypanosoma cruzi B13 protein was reportedly recognized by T-cells in individuals bearing HLA-DQA1*0501 [69], suggesting that individual with HLA-DQA1*0501 may clear the parasite better than those without this allele. Another allele, HLA-DQB1*0301, correlated with PSHD resistance (OR $=0.58,95 \% \mathrm{CI}=0.39-0.86, P=0.007)$, but results on this allele were inconsistent. Two studies indicated that DQB1*0301 had a protective effect against PSHD [42,43], while other two studies did not find a significant association [37,41]. The DQA1*0501-DQB1*0301 linkage is also a common haplotype in several studied populations [42,55,70] and may enhance resistance to PSHD development.

In class I, HLA- A1, -A2, -B5, -B8, and -B12 serotypes were significantly associated with an increased risk for PSHD. There was significant linkage disequilibrium of the A1-B8 haplotype in many prior studies of autoimmune disease risk (http://www.absoluteastronomy.com/topics/HLA-A1), further 
supporting the hypothesis that autoimmunity is an important mechanism in the pathogenesis of PSHD.

The results of our pooled OR suggested that DQA1*0101/4 was possibly associated with increased risk of PSHD after pooling analysis $(\mathrm{OR}=2.59,95 \% \mathrm{CI}=0.87-7.72, P=0.087)$ (Table 2), though the two separate studies of DQA1*0101/4 did not identify an increased risk of PSHD. Similarly, DQA1*0103 had a pooled OR of 1.76 with a 95\%CI of $0.95-3.25$ and $P$ value of 0.073 even though it was not found to be significantly associated with PSHD in three separate studies. Therefore, further studies are required to clarify these variants.

DQA1*0601, DRB1*1202, and DRB1*1302 were determined to have conflicting effects on PSHD in previous studies, and we found no significant association between these alleles and PSHD in our meta-analyses (Fig. 2C). Other HLA markers, including DQB1*0503.1, DQB1*0601, and DRB1*1101, were found to have a significant association with PSHD in at least one study, but we did not identify a significant relationships between any of these alleles and PSHD after pooling the data for our meta-analysis (Table 2). This variation can be attributed to low statistical power and variability in study designs, diagnoses, population selection, and phenotype definitions.

Table 2 also summarizes the results of Egger's test for publication bias. No evidence of publication bias was found for the following significant alleles, DQB1*0303, A1, A2, B5, B8, and B12 $(P>0.1)$. The funnel plot analysis was further performed to detect publication bias of each study for HLA-A1 and HLA-B5, respectively. The shape of the funnel plot seemed to be symmetrical, further suggesting that no publication bias was found in studies of HLA-A1 and HLA-B5 (Fig. 3). There was some indication of publication bias for the studies of DQB1*0301 using Egger's test $(P=0.048$, Table 2$)$. Removing either 
the study by Zhang et al. or the one by McManus et al. resulted in a loss of the publication bias (P $>0.1)$, but it had little effect on the pooled ORs and 95\%CIs; in contrast, removing either the study by Waine et al. or the one by Hirayama et al. led to an increased chance of publication bias $(P=0.038$ and 0.022 , respectively). One limitation of our study is that the publication bias could not be assessed for three significant alleles, DQA1*0501, DRB1*0901 and DQB1*0201, because there were fewer than three studies for each variant. Moreover, non-significant association must be interpreted with cautious for DPA1*0103, DPA1*0201, DQA1*0601, DQB1*0601, DRB1*1202, DRB1*1302, A9, B15 and BW40 variants because of high Q and I-squared values. Therefore, more studies are required to validate on these variants.

A limitation of many meta-analyses is that studies that reports of non-significant results are less likely to be accepted for publication, and missing data could cause potential bias. As with other complicated diseases, the development of PSHD is probably due to multiple factors, in which allelic variants in different genes may have either additive or conflicting effects. Moreover, other hepatitis diseases, alcohol intake, smoking, and praziquantel treatment doses can all affect the development of PSHD [2], and therefore may have affected our analysis. However, because meta-analyses use selected studies based on defined criteria, they can assess common and significant genetic factors that were not assessed in a systematic way in individual, primary studies. Similar meta-analyses of the genetic studies of pneumococcal and meningococcal infection [71], autoimmune diseases [72,73], and cancer [74] have been already reported. We found no effect of different schistosomal species on the outcome of PSHD; 
however, the number of studies for each allele was small (less than 5), and further studies should focus on this issue.

In conclusion, the association between post-schistosomal hepatic disorder and risk factors including eggs load, lack of treatment, repeated infection and HLA types has been reported in previous studies. However, to the knowledge of the authors this is the first systemic meta-analysis that combines individual studies to improve the strength of the evidence. This meta-analysis identified positive associations between eight HLA types-DQB1*0201, DQB1*0303, DRB1*0901, A1, A2, B5, B8, and B12—and post-schistosomal hepatic disorder and negative associations with two variants, DQA1*0501 and DQB1*0301. Moreover, we identified the possible existence of common antigenic moieties that would be presented to some pathogenic or protective T-cells that could affect the outcome of the disease. Though previous included studies identified a positive association of DRB1*0901 - DQB1*0303 linkage [41] and negative association of DQA1*0501 -DQB1*0301 haplotype [42] with PSHD, we further propose that individuals bearing the DRB1*0901 - DQB1*0201 and A1-B8 haplotypes may be at increased risk for the development of PSHD, but further studies are required to confirm our hypothesis. 


\section{Acknowledgments}

This work was also supported in part by a Grand-in-Aid for Young Scientists (17301870, 2008-2010 for NTH) from the Ministry of Education, Culture, Sports, Science and Technology (MEXT, Japan), and was supported in part by a Grant-in-Aid for Scientific Research from Nagasaki University to NTH (2007-2009). This study was also supported in part by the Global COE Program (2008-2012) and Japan Initiative for Global Research Network on Infectious Diseases (J-GRID) for KH.

\section{Footnotes}

The authors have declared that no competing interests exist. The funders had no role in study design, data collection and analysis, decision to publish, or preparation of the manuscript. 


\section{References}

[1] van der Werf MJ, de Vlas SJ, Brooker S, Looman CW, Nagelkerke NJ, Habbema JD, Engels D. Quantification of clinical morbidity associated with schistosome infection in sub-Saharan Africa. Acta Trop 2003;86 (2-3):125-39.

[2] Ross AG, Bartley PB, Sleigh AC, Olds GR, Li Y, Williams GM, McManus DP. Schistosomiasis. N Engl J Med 2002;346 (16):1212-20.

[3] Steinmann P, Keiser J, Bos R, Tanner M, Utzinger J. Schistosomiasis and water resources development: systematic review, meta-analysis, and estimates of people at risk. Lancet Infect Dis 2006;6 (7):411-25.

[4] King $\mathrm{CH}$, Dickman K, Tisch DJ. Reassessment of the cost of chronic helmintic infection: a meta-analysis of disability-related outcomes in endemic schistosomiasis. Lancet 2005;365 (9470):1561-9.

[5] Gryseels B, Polman K, Clerinx J, Kestens L. Human schistosomiasis. Lancet 2006;368 (9541):1106-18.

[6] Doenhoff MJ, Pica-Mattoccia L. Praziquantel for the treatment of schistosomiasis: its use for control in areas with endemic disease and prospects for drug resistance. Expert Rev Anti Infect Ther 2006;4 (2):199-210.

[7] Caldas IR, Campi-Azevedo AC, Oliveira LF, Silveira AM, Oliveira RC, Gazzinelli G. Human schistosomiasis mansoni: immune responses during acute and chronic phases of the infection. Acta Trop 2008;108 (2-3):109-17. 
[8] Boros DL, Whitfield JR. Enhanced Th1 and dampened Th2 responses synergize to inhibit acute granulomatous and fibrotic responses in murine schistosomiasis mansoni. Infect Immun 1999;67 (3):1187-93.

[9] Bonnard P, Remoue F, Schacht AM, Pialoux G, Riveau G. Association between serum cytokine profiles and schistosomiasis-related hepatic fibrosis: infection by Schistosoma japonicum versus S. mansoni. J Infect Dis 2006;193 (5):748-9; author reply 9-50.

[10] Alves Oliveira LF, Moreno EC, Gazzinelli G, Martins-Filho OA, Silveira AM, Gazzinelli A, Malaquias LC, LoVerde P, Leite PM, Correa-Oliveira R. Cytokine production associated with periportal fibrosis during chronic schistosomiasis mansoni in humans. Infect Immun 2006;74 (2):1215-21.

[11] Jankovic D, Cheever AW, Kullberg MC, Wynn TA, Yap G, Caspar P, Lewis FA, Clynes R, Ravetch JV, Sher A. CD4+ T cell-mediated granulomatous pathology in schistosomiasis is downregulated by a B cell-dependent mechanism requiring Fc receptor signaling. J Exp Med 1998;187 (4):619-29.

[12] Teixeira-Carvalho A, Martins-Filho OA, Peruhype-Magalhaes V, Silveira-Lemos D, Malaquias LC, Oliveira LF, Silveira AM, Gazzinelli A, Gazzinelli G, Correa-Oliveira R. Cytokines, chemokine receptors, CD4+CD25HIGH+ T-cells and clinical forms of human schistosomiasis. Acta Trop 2008;108 (2-3):139-49.

[13] Ji F, Liu Z, Cao J, Li N, Liu Z, Zuo J, Chen Y, Wang X, Sun J. B cell response is required for granuloma formation in the early infection of Schistosoma japonicum. PLoS One 2008;3 
(3):e1724.

[14] Dessein A, Chevillard C, Arnaud V, Hou X, Hamdoun AA, Dessein H, He H, Abdelmaboud SA, Luo X, Li J, Varoquaux A, Mergani A, Abdelwahed M, Zhou J, Monis A, Pitta MG, Gasmelseed N, Cabantous S, Zhao Y, Prata A, Brandt C, Elwali NE, Argiro L, Li Y. Variants of CTGF are associated with hepatic fibrosis in Chinese, Sudanese, and Brazilians infected with schistosomes. J Exp Med 2009;206 (11):2321-8.

[15] Burke ML, Jones MK, Gobert GN, Li YS, Ellis MK, McManus DP. Immunopathogenesis of human schistosomiasis. Parasite Immunol 2009;31 (4):163-76.

[16] Elsammak MY, Al-Sharkaweey RM, Ragab MS, Amin GM, Kandil MH. In Egyptians, a mutation in the lymphotoxin-alpha gene may increase susceptibility to hepatitis $\mathrm{C}$ virus but not that to schistosomal infection. Ann Trop Med Parasitol 2008;102 (8):709-16.

[17] Deville WL, Buntinx F, Bouter LM, Montori VM, de Vet HC, van der Windt DA, Bezemer PD. Conducting systematic reviews of diagnostic studies: didactic guidelines. BMC Med Res Methodol 2002;2:9.

[18] Laird NM, Lange C. Family-based designs in the age of large-scale gene-association studies. Nat Rev Genet 2006;7 (5):385-94.

[19] Little J, Bradley L, Bray MS, Clyne M, Dorman J, Ellsworth DL, Hanson J, Khoury M, Lau J, O'Brien TR, Rothman N, Stroup D, Taioli E, Thomas D, Vainio H, Wacholder S, Weinberg C. Reporting, appraising, and integrating data on genotype prevalence and gene-disease associations. Am J Epidemiol 2002;156 (4):300-10. 
[20] Zintzaras E, Lau J. Synthesis of genetic association studies for pertinent gene-disease associations requires appropriate methodological and statistical approaches. J Clin Epidemiol 2008;61 (7):634-45.

[21] Higgins JP, Thompson SG, Deeks JJ, Altman DG. Measuring inconsistency in meta-analyses. Bmj 2003;327 (7414):557-60.

[22] Munafo MR, Flint J. Meta-analysis of genetic association studies. Trends Genet 2004;20 (9):439-44.

[23] Perneger TV. What's wrong with Bonferroni adjustments. Bmj 1998;316 (7139):1236-8.

[24] Nakagawa S. A farewell to Bonferroni: the problems of low statistical power and publication bias. Behavioral Ecology 2004;15 (6):1044-5.

[25] Peters JL, Sutton AJ, Jones DR, Abrams KR, Rushton L. Comparison of two methods to detect publication bias in meta-analysis. Jama 2006;295 (6):676-80.

[26] Egger M, Davey Smith G, Schneider M, Minder C. Bias in meta-analysis detected by a simple, graphical test. Bmj 1997;315 (7109):629-34.

[27] Begg CB, Mazumdar M. Operating characteristics of a rank correlation test for publication bias. Biometrics 1994;50 (4):1088-101.

[28] Dessein AJ, Hillaire D, Elwali NE, Marquet S, Mohamed-Ali Q, Mirghani A, Henri S, Abdelhameed AA, Saeed OK, Magzoub MM, Abel L. Severe hepatic fibrosis in Schistosoma mansoni infection is controlled by a major locus that is closely linked to the interferon-gamma receptor gene. Am J Hum Genet 1999;65 (3):709-21. 
[29] Secor WE, del Corral H, dos Reis MG, Ramos EA, Zimon AE, Matos EP, Reis EA, do Carmo TM, Hirayama K, David RA, David JR, Harn DA, Jr. Association of hepatosplenic schistosomiasis with HLA-DQB1*0201. J Infect Dis 1996;174 (5):1131-5.

[30] Assaad-Khalil SH, Helmy MA, Zaki A, Mikhail MM, el-Hai MA, el-Sawy M. Some genetic, clinical and immunologic interrelations in schistosomiasis mansoni. Ann Biol Clin (Paris) 1993;51 (6):619-26.

[31] Hirayama K, Chen H, Kikuchi M, Yin T, Itoh M, Gu X, Zhang S, Yuan H. Glycine-valine dimorphism at the 86th amino acid of HLA-DRB1 influenced the prognosis of postschistosomal hepatic fibrosis. J Infect Dis 1998;177 (6):1682-6.

[32] Mohamed-Ali Q, Elwali NE, Abdelhameed AA, Mergani A, Rahoud S, Elagib KE, Saeed OK, Abel L, Magzoub MM, Dessein AJ. Susceptibility to periportal (Symmers) fibrosis in human schistosoma mansoni infections: evidence that intensity and duration of infection, gender, and inherited factors are critical in disease progression. J Infect Dis 1999;180 (4):1298-306.

[33] Dessein AJ, Marquet S, Henri S, El Wali NE, Hillaire D, Rodrigues V, Prata A, Ali QM, Gharib B, de Reggi M, Magzoub MM, Saeed OK, Abdelhameed AA, Abel L. Infection and disease in human schistosomiasis mansoni are under distinct major gene control. Microbes Infect 1999;1 (7):561-7.

[34] Eriksson J, Reimert CM, Kabatereine NB, Kazibwe F, Ireri E, Kadzo H, Eltahir HB, Mohamed AO, Vennervald BJ, Venge P. The $434(\mathrm{G}>\mathrm{C})$ polymorphism within the coding sequence of Eosinophil Cationic Protein (ECP) correlates with the natural course of Schistosoma mansoni infection. Int J Parasitol 2007;37 (12):1359-66. 
[35] Cheng YL, Xu MX, Song WJ, Yang Y, Liu WQ, Li YL, Qiu MY, Wu H. [Microarray DNA chip in analyzing the association between HLA-DRB and advanced hepatosplenic schistosomiasis]. Zhongguo Ji Sheng Chong Xue Yu Ji Sheng Chong Bing Za Zhi 2005;23 (6):392-5.

[36] Blanton RE, Salam EA, Ehsan A, King CH, Goddard KA. Schistosomal hepatic fibrosis and the interferon gamma receptor: a linkage analysis using single-nucleotide polymorphic markers. Eur J Hum Genet 2005;13 (5):660-8.

[37] Zhang JH, Liu WQ, Li YL, Long XC. [Studies on the association of human leukocyte antigen class II alleles with advanced hepatosplenic schistosomiasis japonica]. Zhongguo Ji Sheng Chong Xue Yu Ji Sheng Chong Bing Za Zhi 2005;23 (1):6-9.

[38] Chevillard C, Moukoko CE, Elwali NE, Bream JH, Kouriba B, Argiro L, Rahoud S, Mergani A, Henri S, Gaudart J, Mohamed-Ali Q, Young HA, Dessein AJ. IFN-gamma polymorphisms (IFN-gamma +2109 and IFN-gamma +3810) are associated with severe hepatic fibrosis in human hepatic schistosomiasis (Schistosoma mansoni). J Immunol 2003;171 (10):5596-601.

[39] Moukoko CE, El Wali N, Saeed OK, Mohamed-Ali Q, Gaudart J, Dessein AJ, Chevillard C. No evidence for a major effect of tumor necrosis factor alpha gene polymorphisms in periportal fibrosis caused by Schistosoma mansoni infection. Infect Immun 2003;71 (10):5456-60.

[40] Hirayama K. Genetic factors associated with development of cerebral malaria and fibrotic schistosomiasis. Korean J Parasitol 2002;40 (4):165-72.

[41] McManus DP, Ross AG, Williams GM, Sleigh AC, Wiest P, Erlich H, Trachtenberg E, Guanling W, McGarvey ST, Li YS, Waine GJ. HLA class II antigens positively and negatively associated with 
hepatosplenic schistosomiasis in a Chinese population. Int J Parasitol 2001;31 (7):674-80.

[42] Hirayama K, Chen H, Kikuchi M, Yin T, Gu X, Liu J, Zhang S, Yuan H. HLA-DR-DQ alleles and HLA-DP alleles are independently associated with susceptibility to different stages of post-schistosomal hepatic fibrosis in the Chinese population. Tissue Antigens 1999;53 (3):269-74.

[43] Waine GJ, Ross AG, Williams GM, Sleigh AC, McManus DP. HLA class II antigens are associated with resistance or susceptibility to hepatosplenic disease in a Chinese population infected with Schistosoma japonicum. Int J Parasitol 1998;28 (4):537-42.

[44] Hafez M, Aboul Hassan S, el-Tahan H, el-Shennawy F, Khashaba M, al-Tonbary Y, el-Morsi Z, el-Sallab S, el-Desoky I, el-Shazly A, et al. Immunogenetic susceptibility for post-schistosomal hepatic fibrosis. Am J Trop Med Hyg 1991;44 (4):424-33.

[45] Cabello PH, Krieger H, Lopes JD, Sant'Ana EJ. On the association between HLA-A1 and B5 and clinical forms of schistosomiasis mansoni. Mem Inst Oswaldo Cruz 1991;86 (1):37-40.

[46] Abdel-Salam E, Abdel Khalik A, Abdel-Meguid A, Barakat W, Mahmoud AA. Association of HLA class I antigens (A1, B5, B8 and CW2) with disease manifestations and infection in human schistosomiasis mansoni in Egypt. Tissue Antigens 1986;27 (3):142-6.

[47] Wang CG, Zhu QY, Hang PY, Zhu YW, Wang JW, Shen YP, Yang SJ, Chao JY. HLA and schistosomiasis japonica. Chin Med J (Engl) 1984;97 (8):603-5.

[48] El-Tayeb S, Nasr E, Soliman S. HLA and bilharzial liver disease. J Haematol 1982;7:1-5.

[49] Salam EA, Ishaac S, Mahmoud AA. Histocompatibilty-linked susceptibility for hepatospleenomegaly in human schistosomiasis mansoni. J Immunol 1979;123 (4):1829-31. 
[50] The use of diagnostic ultrasound in schistosomiasis--attempts at standardization of methodology. Cairo Working Group. Acta Trop 1992;51 (1):45-63.

[51] Grubic Z, Zunec R, Peros-Golubicic T, Tekavec-Trkanjec J, Martinez N, Alilovic M, Smojver-Jezek S, Kerhin-Brkljacic V. HLA class I and class II frequencies in patients with sarcoidosis from Croatia: role of HLA-B8, -DRB1*0301, and -DQB1*0201 haplotype in clinical variations of the disease. Tissue Antigens 2007;70 (4):301-6.

[52] Harraga S, Godot V, Bresson-Hadni S, Mantion G, Vuitton DA. Profile of cytokine production within the periparasitic granuloma in human alveolar echinococcosis. Acta Trop 2003;85 (2):231-6.

[53] Martinetti M, Tinelli C, Kolek V, Cuccia M, Salvaneschi L, Pasturenzi L, Semenzato G, Cipriani A, Bartova A, Luisetti M. "The sarcoidosis map": a joint survey of clinical and immunogenetic findings in two European countries. Am J Respir Crit Care Med 1995;152 (2):557-64.

[54] Hue S, Cacoub P, Renou C, Halfon P, Thibault V, Charlotte F, Picon M, Rifflet H, Piette JC, Pol S, Caillat-Zucman S. Human leukocyte antigen class II alleles may contribute to the severity of hepatitis C virus-related liver disease. J Infect Dis 2002;186 (1):106-9.

[55] Yu RB, Hong X, Ding WL, Tan YF, Zhang YX, Sun NX, Wu GL, Zhan SW, Ge DF. The association between the genetic polymorphism of HLA-DQA1, DQB1, and DRB1 and serum alanine aminotransferase levels in chronic hepatitis C in the Chinese population. J Gastroenterol Hepatol 2008;23 (9):1394-402.

[56] Sharma SK, Balamurugan A, Saha PK, Pandey RM, Mehra NK. Evaluation of clinical and 
immunogenetic risk factors for the development of hepatotoxicity during antituberculosis treatment. Am J Respir Crit Care Med 2002;166 (7):916-9.

[57] Jores RD, Frau F, Cucca F, Grazia Clemente M, Orru S, Rais M, De Virgiliis S, Congia M. HLA-DQB1*0201 homozygosis predisposes to severe intestinal damage in celiac disease. Scand J Gastroenterol 2007;42 (1):48-53.

[58] Caillat-Zucman S, Garchon HJ, Timsit J, Assan R, Boitard C, Djilali-Saiah I, Bougneres P, Bach JF. Age-dependent HLA genetic heterogeneity of type 1 insulin-dependent diabetes mellitus. J Clin Invest 1992;90 (6):2242-50.

[59] Reveille JD, Macleod MJ, Whittington K, Arnett FC. Specific amino acid residues in the second hypervariable region of HLA-DQA1 and DQB1 chain genes promote the Ro (SS-A)/La (SS-B) autoantibody responses. J Immunol 1991;146 (11):3871-6.

[60] Pereira LM, McFarlane BM, Massarolo P, Saleh MG, Bridger C, Spinelli V, Mies S, McFarlane IG. Specific liver autoreactivity in schistosomiasis mansoni. Trans R Soc Trop Med Hyg 1997;91 (3):310-4.

[61] Peng S, Trimble C, Wu L, Pardoll D, Roden R, Hung CF, Wu TC. HLA-DQB1*02-restricted HPV-16 E7 peptide-specific CD4+ T-cell immune responses correlate with regression of HPV-16-associated high-grade squamous intraepithelial lesions. Clin Cancer Res 2007;13 (8):2479-87.

[62] Migot-Nabias F, Fajardy I, Danze PM, Everaere S, Mayombo J, Minh TN, Renaut A, Georges AJ. HLA class II polymorphism in a Gabonese Banzabi population. Tissue Antigens 1999;53 
(6):580-5.

[63] Abdennaji Guenounou B, Loueslati BY, Buhler S, Hmida S, Ennafaa H, Khodjet-Elkhil H, Moojat N, Dridi A, Boukef K, Ben Ammar Elgaaied A, Sanchez-Mazas A. HLA class II genetic diversity in southern Tunisia and the Mediterranean area. Int J Immunogenet 2006;33 (2):93-103.

[64] Chen S, Hu Q, Xie Y, Zhou L, Xiao C, Wu Y, Xu A. Origin of Tibeto-Burman speakers: evidence from HLA allele distribution in Lisu and Nu inhabiting Yunnan of China. Hum Immunol 2007;68 (6):550-9.

[65] Trachtenberg E, Vinson M, Hayes E, Hsu YM, Houtchens K, Erlich H, Klitz W, Hsia Y, Hollenbach J. HLA class I (A, B, C) and class II (DRB1, DQA1, DQB1, DPB1) alleles and haplotypes in the Han from southern China. Tissue Antigens 2007;70 (6):455-63.

[66] Satoh M, Toma H, Sato Y, Kikuchi M, Takara M, Shiroma Y, Kiyuna S, Hirayama K. Production of a high level of specific IgG4 antibody associated with resistance to albendazole treatment in HLA-DRB1*0901-positive patients with strongyloidiasis. Am J Trop Med Hyg 1999;61 (4):668-71.

[67] Neild GH, Rodriguez-Justo M, Wall C, Connolly JO. Hyper-IgG4 disease: report and characterisation of a new disease. BMC Med 2006;4:23.

[68] Silveira AM, Bethony J, Gazzinelli A, Kloos H, Fraga LA, Alvares MC, Prata A, Guerra HL, Loverde PT, Correa-Oliveira R, Gazzinelli G. High levels of IgG4 to Schistosoma mansoni egg antigens in individuals with periportal fibrosis. Am J Trop Med Hyg 2002;66 (5):542-9.

[69] Abel LC, Iwai LK, Viviani W, Bilate AM, Fae KC, Ferreira RC, Goldberg AC, Juliano L, Juliano 
MA, Ianni B, Mady C, Gruber A, Hammer J, Sinigaglia F, Kalil J, Cunha-Neto E. T cell epitope characterization in tandemly repetitive Trypanosoma cruzi B13 protein. Microbes Infect 2005;7 (11-12):1184-95.

[70] Hernandez-Pacheco G, Aguilar-Garcia J, Flores-Dominguez C, Rodriguez-Perez JM, Perez-Hernandez N, Alvarez-Leon E, Reyes PA, Vargas-Alarcon G. MHC class II alleles in Mexican patients with rheumatic heart disease. Int J Cardiol 2003;92 (1):49-54.

[71] Brouwer MC, de Gans J, Heckenberg SG, Zwinderman AH, van der Poll T, van de Beek D. Host genetic susceptibility to pneumococcal and meningococcal disease: a systematic review and meta-analysis. Lancet Infect Dis 2009;9 (1):31-44.

[72] Duarte-Rey C, Pardo AL, Rodriguez-Velosa Y, Mantilla RD, Anaya JM, Rojas-Villarraga A. HLA class II association with autoimmune hepatitis in Latin America: a meta-analysis. Autoimmun Rev 2009;8 (4):325-31.

[73] Castano-Rodriguez N, Diaz-Gallo LM, Pineda-Tamayo R, Rojas-Villarraga A, Anaya JM. Meta-analysis of HLA-DRB1 and HLA-DQB1 polymorphisms in Latin American patients with systemic lupus erythematosus. Autoimmun Rev 2008;7 (4):322-30.

[74] Yang YC, Chang TY, Lee YJ, Su TH, Dang CW, Wu CC, Liu HF, Chu CC, Lin M. HLA-DRB1 alleles and cervical squamous cell carcinoma: experimental study and meta-analysis. Hum Immunol 2006;67 (4-5):331-40. 


\section{Figure legends}

Fig. 1. Flow diagram of the search and review process.

Fig. 2. Meta-analysis forest plot showing the pooled odd ratio (OR) for PSHD susceptibility with 95\% confidence intervals (95\% CI) of significant HLA alleles (A), significant HLA serotypes (B) and contrasting effective HLA alleles (C). The size of the plots represents the study size. All HLA variants-DQB1*0201, DQB1*0303, and DRB1*0901 were associated with S. japonicum-induced PSHD in all studies (A), while HLA antigens-A1, A2, B5, B8, and B12 were correlated with S. mansoni-induced PSHD in all studies except one study by Wang et al (B).

Fig. 3. Funnel plots for evaluation of publication bias of HLA-A1 (A) and HLA-B5 (B) where there are at least five studies on the same genetic variation. Each circle represents each study in the meta-analysis. 
Fig. 1 Flow diagram of the searching and reviewing process

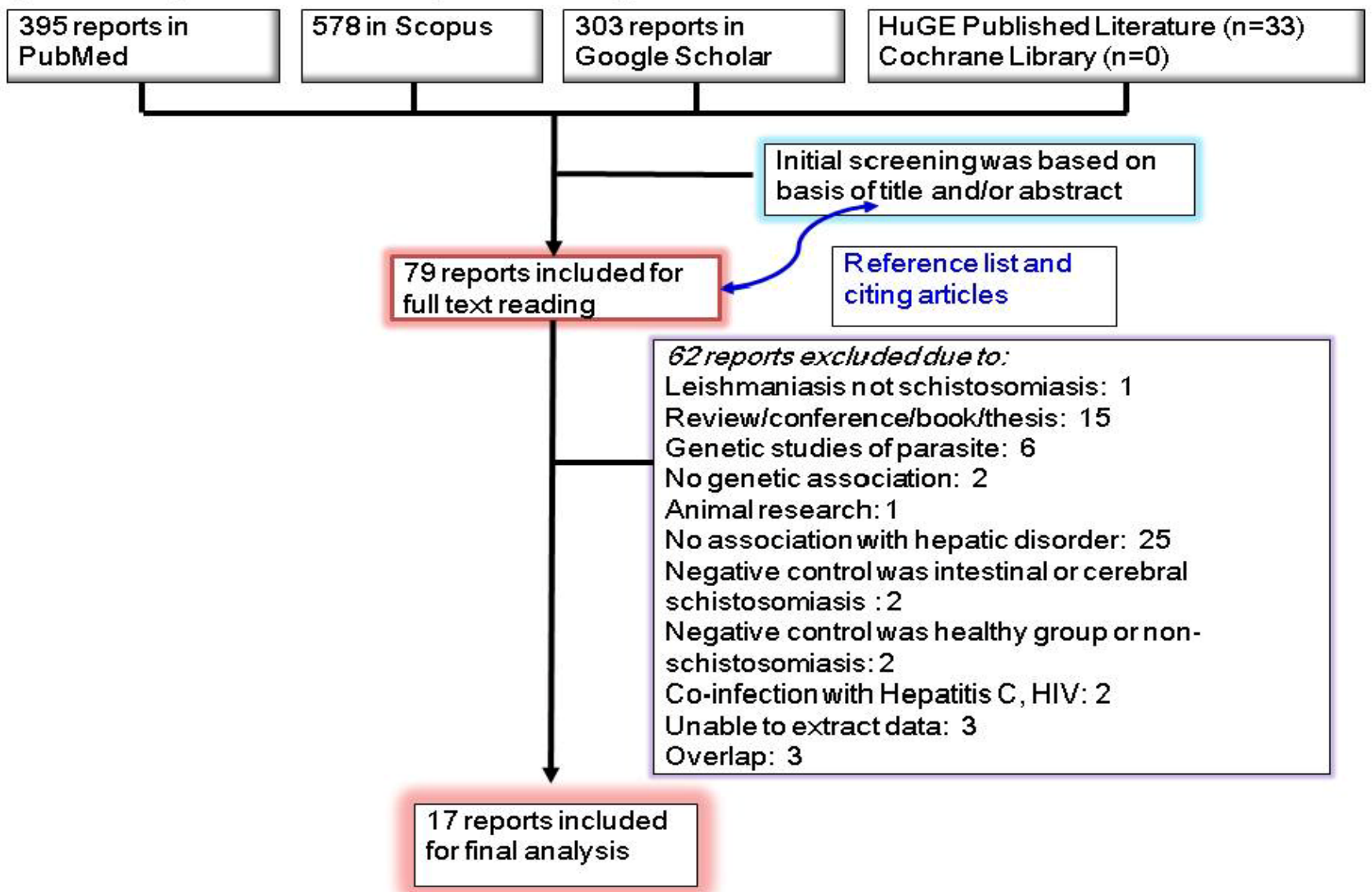


Fig 2 (A)

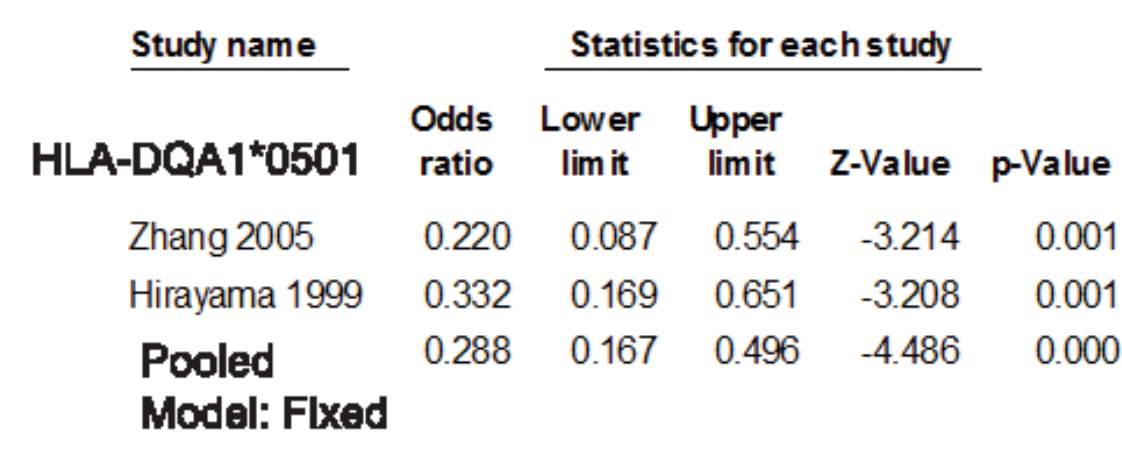

\section{HLA-DQB1"0201}

$\begin{array}{lrrrrr}\text { Zhang 2005 } & 5.833 & 1.542 & 22.073 & 2.597 & 0.009 \\ \text { Hirayama 1999 } & 1.682 & 0.616 & 4.592 & 1.015 & 0.310 \\ \text { Pooled } & 2.641 & 1.185 & 5.888 & 2.375 & 0.018 \\ \text { Model: Flxed } & & & & & \end{array}$

\section{HLA-DQB1*0301}

\begin{tabular}{|c|c|c|c|c|c|}
\hline Zhang 2005 & 1.117 & 0.456 & 2.737 & 0.241 & 0.80 \\
\hline McManus 2001 & 0.953 & 0.394 & 2.302 & -0.107 & 0.91 \\
\hline Hirayama 1999 & 0.354 & 0.180 & 0.697 & -3.004 & 00 \\
\hline Waine 1998 & 0.455 & 0.206 & 1.004 & -1.949 & 0.05 \\
\hline $\begin{array}{l}\text { Pooled } \\
\text { Model: Fixed }\end{array}$ & 0.579 & 0.389 & 0.862 & -2.688 & 0.00 \\
\hline
\end{tabular}

\section{HLA-DQB ${ }^{\star 0} 0303$}

$\begin{array}{lrrrrr}\text { Lhang 2005 } & 1.000 & 0.424 & 2.359 & 0.000 & 1.000 \\ \text { McManus 2001 } & 3.980 & 1.605 & 9.867 & 2.981 & 0.003 \\ \text { Hirayama 1999 } & 1.206 & 0.057 & 25.565 & 0.120 & 0.904 \\ \text { Waine 1998 } & 2.013 & 0.903 & 4.488 & 1.710 & 0.087 \\ \text { Pooled } & 1.930 & 1.187 & 3.138 & 2.651 & 0.008\end{array}$

Model: Fixed
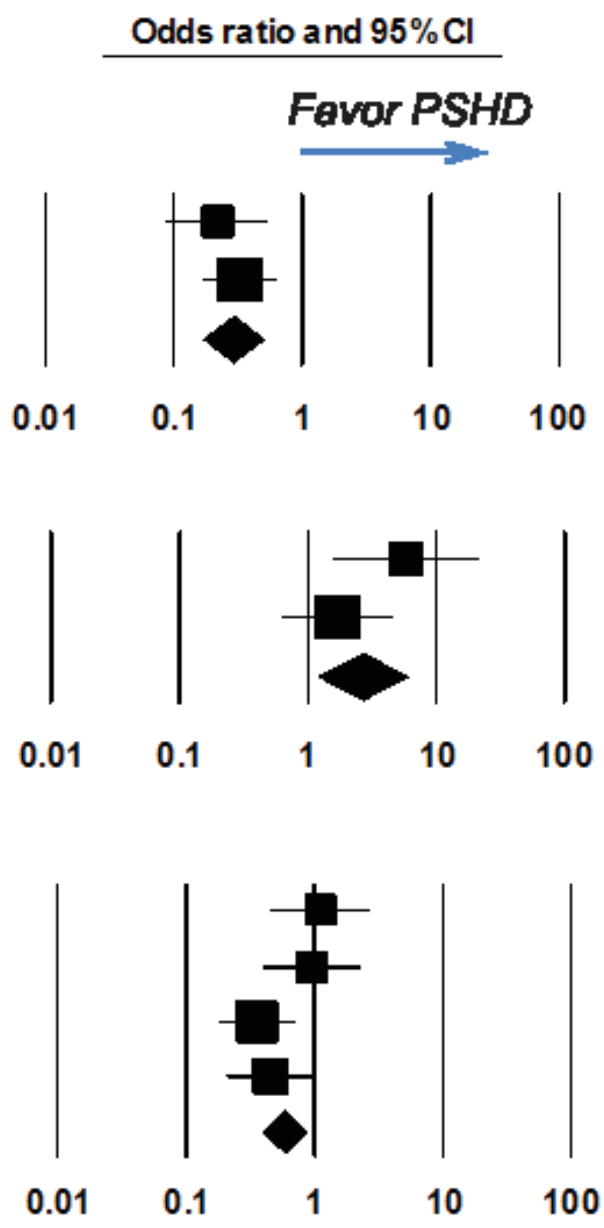

\section{HLA-DRB1ะ0901}

$\begin{array}{llllll}\text { McManus 2001 } & 3.980 & 1.605 & 9.867 & 2.981 & 0.003 \\ \text { Hirayama 1999 } & 1.655 & 0.926 & 2.958 & 1.701 & 0.089 \\ \text { Pooled } & 2.135 & 1.309 & 3.182 & 3.039 & 0.002 \\ \text { Model: Fixed } & & & & & \end{array}$
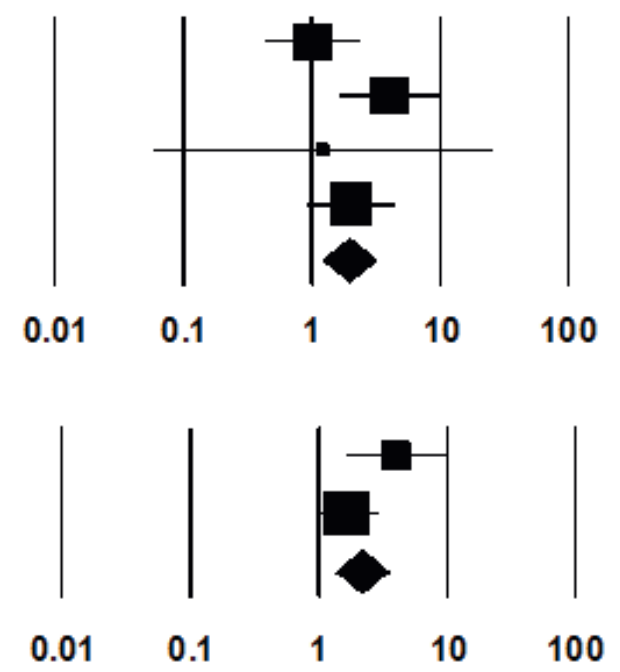
Fig 2(B)

\section{Study name}

HLA-A1

$\begin{array}{lrrrrr}\text { Cabello 1991 } & 2.541 & 0.679 & 9.508 & 1.385 & 0.166 \\ \text { Salam 1986 } & 3.499 & 1.622 & 7.548 & 3.193 & 0.001 \\ \text { Wang 1984 } & 21.000 & 4.198 & 105.038 & 3.707 & 0.000 \\ \text { El-Tayeb 1982 } & 1.436 & 0.269 & 7.678 & 0.423 & 0.672 \\ \text { Salam 1979 } & 29.333 & 3.454 & 249.124 & 3.096 & 0.002 \\ \text { Pooled } & 5.103 & 1.953 & 13.334 & 3.326 & 0.001 \\ \text { Model: Random } & & & & \end{array}$

HLA-A2

Hafez 1991

$$
9.714
$$

$2.080 \quad 45.368$

Salam 1986

2.067

Wang 1984

1.143

0.981

4.352

$0.415 \quad 3.148$

3.429

$0.319 \quad 36.828$

2.170

$1.259 \quad 3.739$

Pooled

Model: Fixed

HLA-B5

Cabello 1991

Salam 1986

18.900

$\begin{array}{ll}3.653 & 97.778\end{array}$

2.569

0.61510 .741

7.917

$3.297 \quad 19.012$

Wang 1984

El-Tayeb 1982

1.408

$0.445 \quad 4.453$

4.923

0.48949 .611

4.630

Pooled

\section{Model: Random}

\section{HLA-B8}

Salam 1986

$$
3.474
$$

$$
\begin{array}{ll}
0.743 & 16.241
\end{array}
$$

1.582

0.000

3.505

1.293

4.629

0.583

1.352

3.265

Wang 1984

1.000

$0.185 \quad 5.403$

2.357

Pooled

Model: Fixed

2.327
0.000

0.196

0.000

0.560

0.176

0.001
Odds ratio and $95 \% \mathrm{Cl}$

Favor PSHD

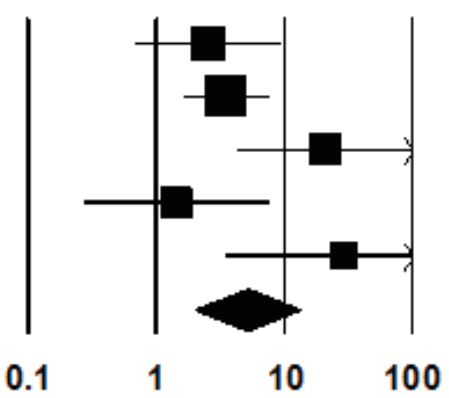

0.01

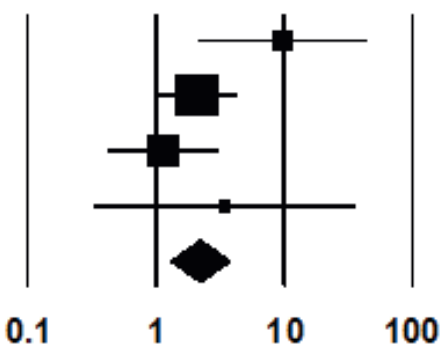

0.01
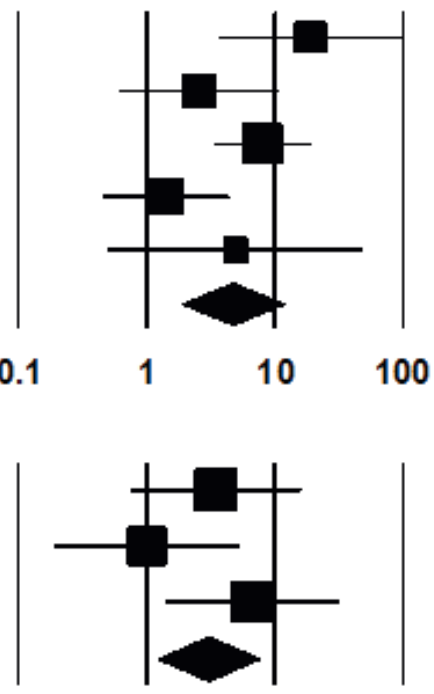

0.01

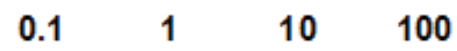

\section{HLA-B12}

$\begin{array}{lrrrrr}\text { Hafez 1991 } & 19.500 & 3.381 & 112.452 & 3.323 & 0.001 \\ \text { Wang 1984 } & 1.556 & 0.241 & 10.049 & 0.464 & 0.643 \\ \text { El-Tayeb 1982 } & 3.182 & 0.121 & 83.760 & 0.694 & 0.488 \\ \quad \begin{array}{l}\text { Pooled } \\ \text { Model: Fixed }\end{array} & 5.487 & 1.670 & 18.029 & 2.805 & 0.005\end{array}$
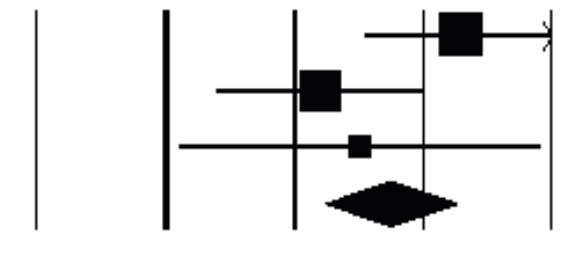

0.01

$\begin{array}{lll}0.1 & 1 & 10\end{array}$

100 
Fig 2(C)

\begin{tabular}{cccccccc} 
Study name & \multicolumn{5}{c}{ Statistics for eachstudy } \\
\cline { 5 - 7 } HLA-DQA1*0601 & $\begin{array}{c}\text { Odds } \\
\text { ratio }\end{array}$ & $\begin{array}{c}\text { Lower } \\
\text { limit }\end{array}$ & $\begin{array}{c}\text { Upper } \\
\text { limit }\end{array}$ & Z-Value & p-Value \\
Zhang 2005 & 8.076 & 1.701 & 38.342 & 2.628 & 0.009 \\
Hirayama 1999 & 1.075 & 0.415 & 2.789 & 0.150 & 0.881 \\
Waine 1998 & 0.195 & 0.072 & 0.526 & -3.229 & 0.001 \\
Pooled & 1.098 & 0.167 & 7.225 & 0.097 & 0.922 \\
Model: Random & & & & &
\end{tabular}

HLA-DRB1*1202

$\begin{array}{lrrrrr}\text { McManus 2001 } & 1.108 & 0.211 & 5.833 & 0.121 & 0.904 \\ \text { Hirayama 1999 } & 2.275 & 0.843 & 6.137 & 1.623 & 0.105 \\ \text { Waine 1998 } & 0.199 & 0.074 & 0.536 & -3.192 & 0.001 \\ \text { Pooled } & 0.777 & 0.149 & 4.055 & -0.300 & 0.764\end{array}$

Odds ratio and $95 \% \mathrm{Cl}$

\section{Favor PSHD}

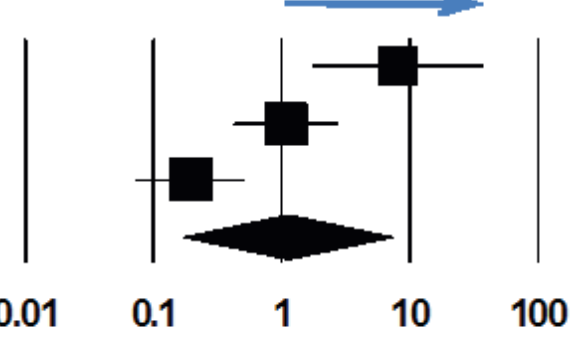

Model: Random

\section{HLA-DRB 1*1302}

$\begin{array}{lrrrrr}\text { McManus 2001 } & 7.588 & 0.871 & 66.080 & 1.835 & 0.066 \\ \text { Hirayama 1999 } & 1.188 & 0.135 & 10.431 & 0.155 & 0.877 \\ \text { Waine 1998 } & 0.208 & 0.040 & 1.082 & -1.866 & 0.062 \\ \text { Pooled } & 1.126 & 0.135 & 9.362 & 0.110 & 0.913\end{array}$

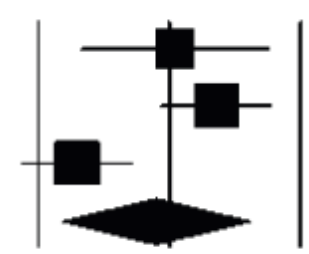

Model: Random 
Fig 3
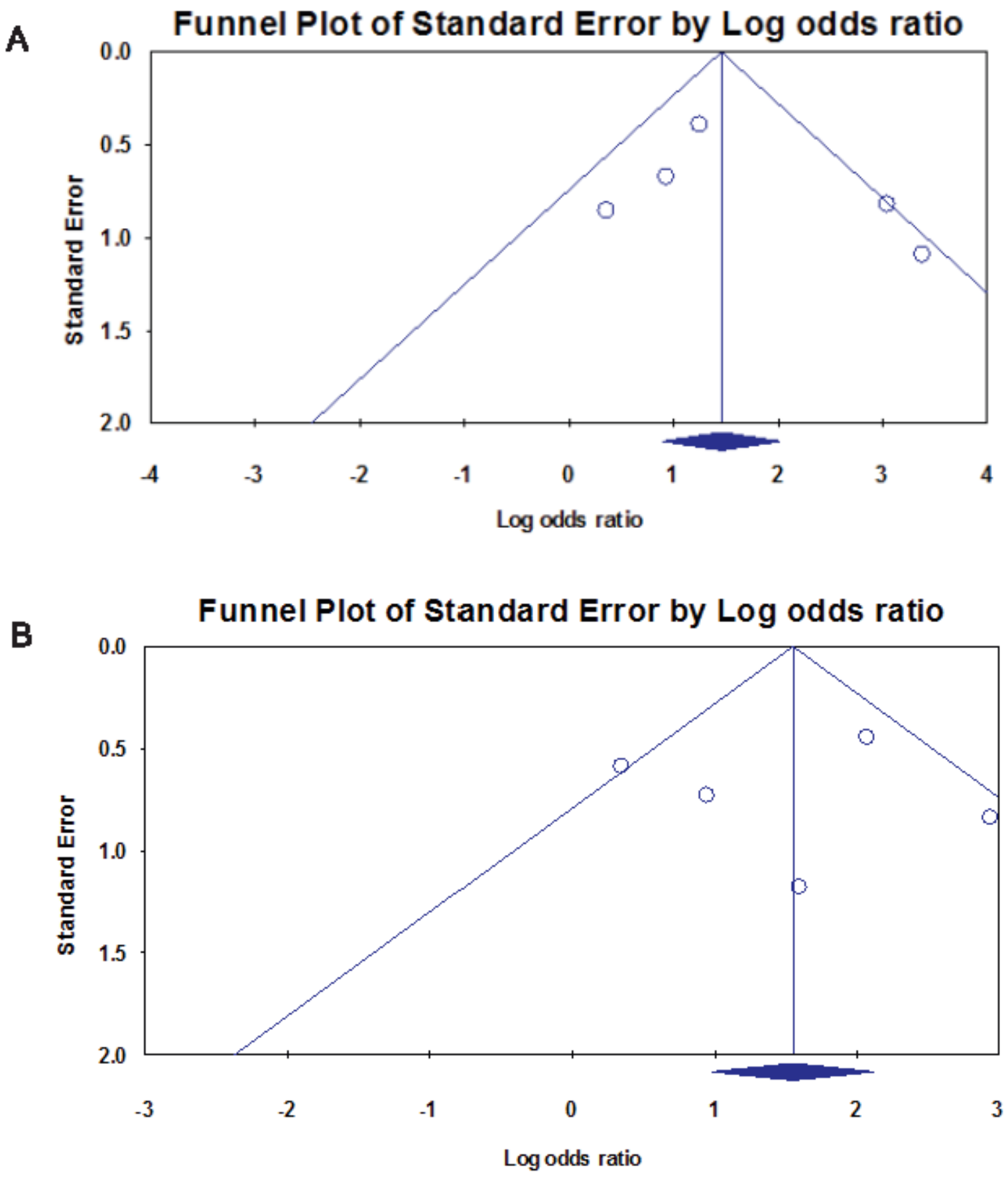


\begin{tabular}{|c|c|c|c|c|c|c|c|c|c|c|c|}
\hline \multirow{3}{*}{ Authors } & \multirow{3}{*}{ Year } & \multirow{3}{*}{ Country } & \multirow{3}{*}{ Strain } & \multirow{3}{*}{ Study design } & \multicolumn{2}{|l|}{ PSHD } & \multicolumn{2}{|l|}{ Control } & \multirow{3}{*}{$\begin{array}{l}\text { Diagnostic } \\
\text { method of } \\
\text { PSHD }\end{array}$} & \multirow{3}{*}{$\begin{array}{l}\text { Genetic } \\
\text { method }\end{array}$} & \multirow{3}{*}{$\begin{array}{l}\text { Number } \\
\text { alleles } \\
\text { studied }\end{array}$} \\
\hline & & & & & \multirow{2}{*}{$\begin{array}{l}\text { No. } \\
\text { (female\%) }\end{array}$} & Mean age & \multirow{2}{*}{$\begin{array}{l}\text { No. } \\
\text { (female\%) }\end{array}$} & Mean age & & & \\
\hline & & & & & & $\begin{array}{l}( \pm \mathrm{SD} \\
\text { range) }\end{array}$ & & $\begin{array}{l}( \pm \mathrm{SD} \quad \text { or } \\
\text { range })\end{array}$ & & & \\
\hline Elsammak & 2008 & Egypt & S. mansoni & Case control & $22(41)$ & $53.7( \pm 5.6)$ & $22(41)$ & $48.5( \pm 5.4)$ & Ultrasound & PCR-RFLP & $1(\mathrm{LA})$ \\
\hline Eriksson & 2007 & Uganda & S. mansoni & Case control & 22 (ND) & ND & 274(ND) & ND & Ultrasound & PCR-SSOP & 1 (ECP) \\
\hline Cheng & 2005 & China & S. japonicum & Case control & $45(31)$ & $54.9( \pm 11)$ & $44(34)$ & $51.6( \pm 9.2)$ & ND & PCR-SSOP & 16 (HLA) \\
\hline Blanton & 2005 & Egypt & S. mansoni & Family based & 48 (25) & $42.3( \pm 15)$ & 188(33) & $39.1( \pm 13.2)$ & Ultrasound & UTSG & 48(11genes) \\
\hline Zhang & 2005 & China & S. japonicum & Case control & $46(41)$ & $51.8( \pm 10)$. & $43(30)$ & $55.3( \pm 7.8)$ & Ultrasound & PCR-SSOP & 41 (HLA) \\
\hline Chevillard & 2003 & Sudan & S. mansoni & Case control & 29 (ND) & ND & 76 (ND) & ND & Ultrasound & PCR-SSCP & $5(\mathrm{IFN}-\gamma)$ \\
\hline Moukoko & 2003 & Sudan & S. mansoni & Case control & 27 (ND) & ND & 71 (ND) & ND & Ultrasound & PCR-RFLP & 4 (TNF- $\alpha)$ \\
\hline Hirayama & 2002 & China & S. japonicum & Case control & 156 (ND) & ND & 36 (ND) & ND & Ultrasound & ND & 1 (IL-13) \\
\hline McManus & 2001 & China & S. japonicum & Case control & 40 (ND) & ND & 44 (ND) & ND & Ultrasound & PCR-SSOP & 34 (HLA) \\
\hline Hirayama & 1999 & China & S. japonicum & Case control & $186(40)$ & ND & $44(57)$ & ND & Ultrasound & PCR-SSOP & 104 (HLA) \\
\hline Waine & 1998 & China & S. japonicum & Case control & 64 (ND) & $59.4( \pm 8.8)$ & 44 (ND) & $54.5( \pm 7.1)$ & Ultrasound & PCR-SSOP & 53 (HLA) \\
\hline Hafez & 1991 & Egypt & S. mansoni & Case control & $19(26)$ & $11.2(7-14)$ & $20(40)$ & $9.9(7-14)$ & Biopsy & CDM & 29 (HLA) \\
\hline Cabello & 1991 & Brazil & S. mansoni & Case control & 23 (ND) & ND & 41 (ND) & ND & Clinical & $\mathrm{CDM}$ & 38 (HLA) \\
\hline Salam & 1986 & Egypt & S. mansoni & Case control & 88 (ND) & $11.8( \pm 1.1)$ & 46 (ND) & $12.8( \pm 0.5)$ & Biopsy & CDM & 32 (HLA) \\
\hline Wang & 1984 & China & S. japonicum & Case control & 30 (ND) & ND & 30 (ND) & ND & Clinical & $\mathrm{CDM}$ & 24 (HLA) \\
\hline El-Tayeb & 1982 & Egypt & S. mansoni & Case control & 17 (ND) & $37.3(14-60)$ & 17 (ND) & $33.9(14-55)$ & Clinical & CDM & 25 (HLA) \\
\hline Salam & 1979 & Egypt & S. mansoni & Case control & $28(32)$ & ND & $23(26)$ & ND & Clinical & CDM & 37 (HLA) \\
\hline
\end{tabular}

ND, not described

PCR-SSCP, PCR-single strand conformation polymorphism

PCR-RFLP, PCR-restriction fragment length polymorphism

CDM, complement-dependent microlymphocytotoxicity

PCR-SSOP, PCR-sequence-specific oligonucleotides probes

LA, lymphotoxin- $\alpha$

UTSG, ultra-high throughput SNP genotyping

ECP, Eosinophil Cationic Protein 
Table 2. Summary of associations between HLA alleles and hepatic disorders, pooled odds ratios (OR) with corresponding 95\% confidence intervals (95\%CI) of the published results were calculated where more than one study had investigated the allele.

HLA types No. of Heterogeneity Model Association with hepatic disorders Egger's study

2-tailed bias Q value $P$ value I-squared $P$ value $\quad$ OR $\quad 95 \%$ CI

$P$ value

\begin{tabular}{|c|c|c|c|c|c|c|c|c|c|}
\hline DPA1*0103 & 2 & 6.06 & 0.014 & 83.5 & Random & 0.500 & 1.62 & $0.40-6.62$ & ND \\
\hline DPA1*0201 & 2 & 3.80 & 0.051 & 73.7 & Random & 0.893 & 1.22 & 0.06-22.99 & ND \\
\hline DPA1*0401 & 2 & 0.002 & 0.97 & 0 & Fixed & 0.636 & 0.77 & $0.25-2.32$ & ND \\
\hline DQA1*0101 & 2 & 0.00 & 0.993 & 0.0 & Fixed & 0.280 & 0.46 & $0.11-1.88$ & ND \\
\hline DQA1*0101/4 & 2 & 0.83 & 0.362 & 0.0 & Fixed & 0.087 & 2.59 & $0.87-7.72$ & ND \\
\hline DQA1*0102 & 3 & 1.28 & 0.527 & 0.0 & Fixed & 0.670 & 0.89 & $0.51-1.54$ & 0.205 \\
\hline DQA1*0103 & 3 & 1.61 & 0.448 & 0.0 & Fixed & 0.073 & 1.76 & $0.95-3.25$ & 0.21 \\
\hline DQA1*0201 & 3 & 3.48 & 0.175 & 42.6 & Fixed & 0.948 & 1.03 & $0.44-2.40$ & 0.584 \\
\hline DQA1*0301 & 2 & 0.19 & 0.666 & 0.0 & Fixed & 0.389 & 1.43 & $0.64-3.21$ & ND \\
\hline DQA1*0401 & 3 & 3.21 & 0.201 & 37.7 & Fixed & 0.624 & 0.75 & $0.23-2.42$ & 0.052 \\
\hline DQA1*0501 & 2 & 0.50 & 0.480 & 0.0 & Fixed & $<0.0001$ & 0.29 & 0.17-0.50 & ND \\
\hline DQA1*0601 & 3 & 16.57 & 0.000 & 87.9 & Random & 0.922 & 1.10 & $0.17-7.23$ & 0.601 \\
\hline DQB1*0201 & 2 & 2.14 & 0.144 & 53.2 & Fixed & 0.018 & 2.64 & 1.19-5.89 & ND \\
\hline DQB1*0301 & 4 & 5.67 & 0.129 & 47.0 & Fixed & 0.007 & 0.58 & $0.39-0.86$ & 0.048 \\
\hline DQB1*0302 & 4 & 4.12 & 0.249 & 27.1 & Fixed & 0.425 & 0.83 & $0.52-1.32$ & 073 \\
\hline DQB1*0303 & 4 & 4.80 & 0.187 & 37.5 & Fixed & 0.008 & 1.93 & $1.19-3.14$ & 0.91 \\
\hline DQB1*0401 & 3 & 1.93 & 0.380 & 0.0 & Fixed & 0.80 & 1.10 & $0.53-2.30$ & 0.71 \\
\hline DQB1*0402 & 2 & 1.30 & 0.254 & 23.2 & Fixed & 0.29 & 0.32 & $0.04-2.64$ & ND \\
\hline DQB1*0501 & 4 & 3.26 & 0.353 & 8.0 & Fixed & 0.40 & 1.75 & $0.48-6.43$ & 0.11 \\
\hline DQB1*0502 & 4 & 1.54 & 0.672 & 0.0 & Fixed & 0.169 & 0.63 & $0.33-1.22$ & 0.61 \\
\hline DQB1*0503.1 & 3 & 4.47 & 0.107 & 55.2 & Fixed & 0.68 & 1.37 & $0.30-6.23$ & 0.23 \\
\hline DQB1*0601 & 4 & 13.20 & 0.004 & 77.3 & Random & 0.301 & 0.60 & $0.23-1.58$ & 0.92 \\
\hline DQB1*0602 & 4 & 4.37 & 0.224 & 31.4 & Fixed & 0.902 & 0.96 & $0.50-1.83$ & 0.62 \\
\hline DQB1*0603 & 3 & 2.53 & 0.283 & 20.9 & Fixed & 0.254 & 2.73 & $0.49-15.33$ & 0.20 \\
\hline DQB1*0604 & 3 & 2.45 & 0.294 & 18.3 & Fixed & 0.501 & 0.55 & 0.09-3.19 & 0.93 \\
\hline DRB1*01 & 3 & 1.69 & 0.429 & 0.0 & Fixed & 0.848 & 0.85 & $0.16-4.48$ & 0.33 \\
\hline DRB1*0301 & 3 & 4.60 & 0.100 & 56.5 & Random & 0.32 & 2.33 & $0.44-12.34$ & 0.19 \\
\hline DRB1*0401 & 2 & 0.62 & 0.433 & 0.0 & Fixed & 0.95 & 1.06 & $0.18-6.21$ & ND \\
\hline DRB1*0403 & 3 & 2.08 & 0.353 & 3.8 & Fixed & 0.56 & 1.38 & $0.47-4.05$ & 0.115 \\
\hline DRB1*0404 & 3 & 1.38 & 0.502 & 0.0 & Fixed & 0.174 & 0.34 & $0.07-1.62$ & 0.98 \\
\hline DRB1*0405 & 3 & 0.97 & 0.614 & 0.0 & Fixed & 0.42 & 1.35 & $0.66-2.78$ & 0.49 \\
\hline DRB1*0406 & 3 & 1.99 & 0.370 & 0.0 & Fixed & 0.46 & 1.56 & $0.48-5.05$ & 0.39 \\
\hline DRB1*0701 & 3 & 2.35 & 0.309 & 14.8 & Fixed & 0.661 & 0.81 & $0.31-2.11$ & 0.22 \\
\hline $\mathrm{DRB} 1 * 0901^{\mathrm{a}}$ & 3 & 3.88 & 0.144 & 48.4 & Fixed & 0.49 & 1.18 & $0.75-1.86$ & 0.85 \\
\hline
\end{tabular}




\begin{tabular}{|c|c|c|c|c|c|c|c|c|c|}
\hline DRB1*0901 ${ }^{b}$ & 2 & 2.54 & 0.111 & 60.7 & Fixed & 0.002 & 2.39 & $1.31-3.48$ & ND \\
\hline DRB1*1001 & 4 & 2.52 & 0.472 & 0.0 & Fixed & 0.91 & 0.92 & $0.25-3.46$ & 0.09 \\
\hline DRB1*1101 & 3 & 4.77 & 0.092 & 58.1 & Random & 0.162 & 0.46 & $0.15-1.37$ & 0.004 \\
\hline DRB1*1104 & 2 & 1.34 & 0.247 & 25.4 & Fixed & 0.91 & 0.88 & $0.09-8.58$ & ND \\
\hline DRB1*1201 & 3 & 4.09 & 0.130 & 51.1 & Fixed & 0.87 & 1.08 & $0.45-2.62$ & 0.31 \\
\hline DRB1*1202 & 3 & 11.89 & 0.003 & 83.2 & Random & 0.76 & 0.78 & $0.15-4.06$ & 0.90 \\
\hline DRB1*1301 & 2 & 1.53 & 0.215 & 34.8 & Fixed & 0.42 & 2.42 & $0.28-20.94$ & ND \\
\hline DRB1*1302 & 3 & 6.82 & 0.033 & 70.7 & Random & 0.91 & 1.13 & $0.14-9.36$ & 0.31 \\
\hline DRB1*1401 & 3 & 1.06 & 0.589 & 0.0 & Fixed & 0.55 & 0.61 & $0.12-3.07$ & 0.79 \\
\hline DRB1*1403 & 2 & 0.04 & 0.843 & 0.0 & Fixed & 0.24 & 0.28 & $0.03-2.31$ & ND \\
\hline DRB1*1404 & 2 & 0.09 & 0.767 & 0.0 & Fixed & 0.69 & 1.43 & $0.24-8.65$ & ND \\
\hline DRB1*1405 & 3 & 2.46 & 0.293 & 18.6 & Fixed & 0.69 & 1.38 & $0.29-6.43$ & 0.19 \\
\hline DRB1*1407 & 2 & 1.69 & 0.194 & 40.7 & Fixed & 0.84 & 0.81 & $0.10-6.36$ & ND \\
\hline DRB1*1501 & 3 & 7.62 & 0.022 & 73.7 & Random & 0.76 & 0.83 & $0.24-2.89$ & 0.62 \\
\hline DRB1*1502 & 2 & 2.56 & 0.110 & 60.9 & Fixed & 0.80 & 1.31 & $0.16-10.58$ & ND \\
\hline DRB1*1602 & 3 & 1.31 & 0.518 & 0.0 & Fixed & 0.64 & 0.80 & $031-2.06$ & 0.71 \\
\hline A1 & 5 & 9.35 & 0.053 & 57.2 & Random & 0.001 & 5.10 & $1.95-13.33$ & 0.44 \\
\hline A2 & 4 & 5.33 & 0.149 & 43.7 & Fixed & 0.005 & 2.17 & $1.26-3.74$ & 0.48 \\
\hline A3 & 2 & 0.12 & 0.733 & 0.0 & Fixed & 0.45 & 0.52 & $0.10-2.75$ & ND \\
\hline A9 & 3 & 4.65 & 0.098 & 57.0 & Random & 0.72 & 1.45 & $0.26-1.38$ & 0.002 \\
\hline A11 & 2 & 1.80 & 0.180 & 44.5 & Fixed & 0.76 & 1.16 & $0.45-2.97$ & ND \\
\hline A28 & 2 & 0.26 & 0.608 & 0.0 & Fixed & 0.65 & 1.64 & 0.19-13.99 & ND \\
\hline AW30+31 & 2 & 0.00 & 0.991 & 0.0 & Fixed & 0.33 & 3.14 & $0.31-31.39$ & ND \\
\hline B5 & 5 & 9.01 & 0.061 & 55.6 & Random & 0.001 & 4.63 & $1.85-11.62$ & 0.99 \\
\hline B7 & 2 & 0.81 & 0.369 & 0.0 & Fixed & 0.74 & 1.25 & $0.34-4.61$ & ND \\
\hline B8 & 3 & 2.65 & 0.266 & 24.5 & Fixed & 0.02 & 2.99 & $1.19-7.53$ & 0.39 \\
\hline B12 & 3 & 3.87 & 0.144 & 48.4 & Fixed & 0.005 & 5.49 & $1.67-18.03$ & 0.82 \\
\hline B13 & 2 & 1.61 & 0.205 & 37.7 & Fixed & 0.24 & 1.82 & $0.68-4.90$ & ND \\
\hline B15 & 2 & 4.21 & 0.040 & 76.2 & Random & 0.95 & 1.13 & $0.04-31.86$ & ND \\
\hline B17 & 2 & 1.33 & 0.249 & 24.7 & Fixed & 0.53 & 1.57 & $0.38-6.51$ & ND \\
\hline BW22 & 2 & 1.69 & 0.193 & 41.0 & Fixed & 0.59 & 0.68 & $0.17-2.77$ & ND \\
\hline BW40 & 2 & 2.71 & 0.100 & 63.1 & Random & 0.57 & 1.97 & 0.19-19.97 & ND \\
\hline
\end{tabular}

afibrosis FI-III vs. F0

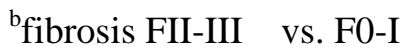

OR, pooled odds ratio

95\%CI, 95\% confidence interval

ND, not performed when there is less than three studies

Bold line indicates significant association 